\title{
Ejes para pensar la Matriz Histórico-Crítica en la formación del Trabajador Sociala en Paraguay
}

\section{Basis to think about the Historical-Critical Matrix in the formation of the Social Worker in Paraguay}

\author{
Carmen García ${ }^{b}$, Ada Vera ${ }^{b}$
}

\begin{abstract}
Resumen
El objetivo del presente trabajo es colocar algunos aspectos teorico contextuales necesarios para abordar la perspectiva histórico-crítica del trabajo social atendiendo las particularidades del proceso paraguayo; reconociendo la inexistencia de tradiciones en el pensamiento social paraguayo que posibiliten la comprensión de la formación social desde una visión de totalidad. En ese sentido, el proceso curricular llevado acabo imprime al espacio de formación un horizonte desafiador y en gran medida depende de la interpretación de sus actores para generar sentidos que muestran distintas formas de ver determinados tipos de trabajo social con perspectiva crítica Palabras clave: trabajo Social, formación profesional, capitalismo, matriz crítica, proceso paraguayo.
\end{abstract}

Palabras clave: trabajo social, formación profesional, capitalismo, matriz crítica, proceso paraguayo.

\begin{abstract}
Abstrac
The objective of the present work is to place some theoretical contextual aspects necessary to approach the historical-critical perspective of social work taking into account the peculiarities of the Paraguayan process. Recognizing the inexistence of traditions in Paraguayan social thought that make possible the understanding of social formation from a vision of totality. In that sense, the curricular process carried out gives the training space a challenging horizon and it depends on the interpretation of its actors to generate meanings that show different ways of seeing certain types of social work with a critical perspective.
\end{abstract}

Keywords: social work, professional training, capitalism, critical matrix, paraguayan process.

\section{Introducción}

Este artículo se centra sobre las reflexiones generadas a partir de la investigación: Matrices Teóricas presentes
Kera Yvoty: reflexiones sobre la cuestión social. Vol. 1, 2016,

ISSN (impreso): 2519-7797

a En este artículo no se utilizará lenguaje de géneros diferenciados, siempre se hablará de 'el trabajador social' en forma genérica.

b Universidad Nacional de Asunción, Instituto de Trabajo Social, Paraguay.

Correspondencia a: carmetea72@gmail.com

Cita:

García, C. \& Vera, A. (2016).

Ejes para pensar la matriz histórico-crítica en la formación del Trabajador Social el en Paraguay. Kera Yvoty: reflexiones sobre la cuestión social, 1, 31-42.

Recibido:

22 setiembre 2016

Aceptado:

27 octubre 2016 
en la formación profesional del Trabajo Social del Instituto de Trabajo Social de la Universidad Nacional de Asunción. El proyecto de investigación mencionado es el primero desarrollado en el ITS-UNA, desde la creación de la Dirección de Investigación en el 2014, por lo que revierte de un carácter incipiente, preliminar y no conclusivo.

Es pertinente recordar que en el año 2001 el cambio curricular de la carrera de Trabajo Social asume la matriz crítica que ubica a la profesión en la división social y técnica del trabajo donde le compete la implementación de políticas sociales de asistencia, de promoción, en espacios micro pudiendo el y la profesional participar no apenas en la ejecución terminal de dicha política, sino en la formulación, evaluación y redefinición de las mismas (Diseño Curricular de la Escuela de Trabajo Social 2001 Res N 8542-00-01). Otro de los pilares como matriz curricular fue la perspectiva Socio-reconstruccionista. Estos dos pilares nuevamente son reafirmados en el nuevo Currículo revisado y aprobado por el Rectorado de la Universidad Nacional de Asunción para su implementación, desde el año 2016 en adelante.

Este trabajo se funda en la idea que el Trabajo Social se origina y desarrolla "como una profesión volcada para la intervención en la realidad, utilizando conocimientos socialmente acumulados y producidos desde las distintas disciplinas sociales" por lo tanto el trabajador social necesita imprescindiblemente esclarecer los puentes tendientes a articular teoría y práctica. Se torna una exigencia entonces buscar "fundamentos científicos sólidos que orienten la actuación, sobrepasando la pura actividad técnica" (Iamamoto 1997, p. 103).

Por otro lado, hay un consenso de que la intervención profesional está ligada a las distintas formas de conocer y hacer de la acción, es decir "implica superar la dicotomía profesión (hacer) y disciplina (conocer-saber), entender ambas como complementarias", esto supone trascender las ideas que ubican a la profesión a un "que-hacer irreflexivo, empírico, disociado de cualquier mediación teórica, y caracterizado por su estrechez para analizar la realidad y, por tanto, para problematizar" (Muñoz \& Vargas, 2013, p. 122).

El desafío curricular imprime al espacio de formación profesional, un horizonte desafiador a seguir, el cual no está completamente acabado y en gran medida depende de la interpretación de sus actores para generar sentidos que muestran las distintas forma de ver un trabajo social crítico en Paraguay.

Este currículo está inserto en un contexto país marcado por determinadas particularidades que hacen que el pensamiento social crítico no se haya podido desarrollar desde la instancia universitaria. En 1989 cuando la sociedad despertó de la larga dictadura militar de más de 35 años, se inicia un proceso de instalación de instituciones democráticas, el trabajo social como hija de este proceso, inicia también el camino de revisión de su función en la sociedad, entendiéndose que este proceso no ha acabado y está en construcción.

\section{La idea de Trabajo Social y su diálogo con las particularidades del proceso paraguayo}

\subsection{Sobre la idea de Trabajo Social}

Para Iamamoto (1997) el Trabajo Social se origina y desarrolla como una profesión volcada para la intervención en la realidad, utilizando conocimientos socialmente acumulados y producidos desde las distintas disciplinas sociales. Este carácter subalterno hace que como disciplina necesita imprescindiblemente esclarecer los puentes tendientes a articular la teoría y la práctica, tornándose una exigencia buscar fundamentos científicos sólidos que orienten la actuación sobrepasando la pura actividad técnica.

Por tanto en esta perspectiva se vuelve indispensable entender al capitalismo 
y la relación que tiene con el Trabajo Social, considerándolo en su condición de categoría histórica, social y económica, como un modo de producción asociado no solo a la explotación del trabajador, sino también a un sistema de ideas y a una fase histórica del mismo. El elemento crucial que imprime tal sistema son las relaciones sociales, inherentes al modo de producción que determina la división entre el capital y el trabajo, y por lo tanto, de los hombres y mujeres, pasando a diferenciarse ahora por la propiedad de los medios de producción, configurándose así dos clases fundamentales, los dueños de los medios de producción y los trabajadores.

La forma en que la clase hegemónica lleva a cabo sus objetivos en el capitalismo según Netto (1998); tiene que ver con la manutención de las condiciones económicasysociales propicias para avanzar en la acumulación de la riqueza. Para eso; se implementaron diversos mecanismos, en que el Estado refuncionalizó su acción e incidió en la organización políticaeconómica interviniendo sobre las refracciones de la cuestión social de forma continua, estratégica y sistemática con la implementación de políticas sociales. Desde ahí, el trabajador social, fue situado como agente que opera en la implementación de las políticas sociales, en diversas modalidades de intervención, ya sea asistencial, promocional, o gerencial. Es por ello que la cuestión social y el Trabajo Social se emparentan recién cuando el Estado comienza a intervenir a través de sus instituciones.

Por lo tanto para entender el Trabajo Social como categoría histórica, es importante ubicarla como tributaria de un tiempo histórico, marcada por la intervención racionalizada del Estado hacia las manifestaciones de la cuestión social. Y siguiendo a Netto (2002) la cuestión social sólo se torna una cuestión a ser tratada, cuando la acumulación de fuerzas de los trabajadores disputa el escenario político en la segunda mitad del siglo XIX en Europa.
Es decir, es solo cuando uno de los grupos sociales, hijos del proceso de producción que laos crea, se organizan y exigen reconocimiento en la sociedad burguesa que el pauperismo pasa a ser denominado cuestión social y posteriormente a partir de esta denominación se estructura una propuesta de intervención en lo social.

Esta condición de subordinación generada históricamente, sería caótica y sin salida hasta hoy; de no haber sido por los diversos movimientos, búsquedas militantes y académicas generadas en la profesión, sobre todo en América Latina a partir de la segunda mitad del siglo pasado. Uno de los movimientos más fuertes en este sentido ha sido el Movimiento de Reconceptualización en Trabajo Social, el cual se inicia a mediados de la década de 1960 en tres países: Brasil, Uruguay y Argentina, para posteriormente extenderse a toda América Latina hasta finales de los setenta'. Este movimiento cuestionó fuertemente el legado subalterno de la profesión, a la vez que manifestó la necesidad de generar un proceso de revisión y superación de este legado conservador.

Considerando que los debates de la reconceptualización latinoamericana, reconocen y se muestran críticos a la funcionalidad de esta disciplina con el proyecto capitalista (Manrique Castro, 1998), en este continente y también en el país, se ha buscado caminos emancipadores diversos, cuyo efecto de maduración se observa en la producción latinoamericana de los últimos 25 años y constituye el debate actual del Trabajo Social y Paraguay no ha quedado fuera de esta búsqueda.

La interpretación del origen y la institucionalización del Trabajo Social en este país depende enteramente del proceso capitalista de Paraguay como lo plantea García (1997) y coloca la necesidad de recuperar el sentido histórico de los

1 Según plantea Parra (s/f) este es el periodo de auge del movimiento, aunque es polémico el tiempo de finalización. 
procesos, mediante la teoría crítica como en la formación profesional en el ITS-UNA. De esta manera conviene mencionar que el Trabajo Social desde que se embarcó en esta perspectiva lleva casi 2 décadas en la búsqueda de ofrecer solvencia tanto en el ámbito estudiantil, como en el docente, siendo pionera en la instalación de esta perspectiva en el Trabajo Social en Paraguay.

\subsection{Paraguay y su posición en el Capitalismo Internacional}

En la época de la Colonia fue un centro de abastecimiento y desarrollo, que posteriormente fue abandonada a su suerte una vez que las explotaciones de oro y plata dejaron de ser vías de desarrollo para los colonizadores. A partir de allí la historia de Paraguay está marcada fuertemente por la explotación de su población nativa, conocida como la encomienda, el yanaconazgo o la mita.

A partir de su independencia de la colonia española, Paraguay desarrolla uno de los procesos más prósperos de la región. Este desarrollo se ve destruido con la Guerra de la Triple Alianza, evento que a más destruir los recursos productivos, diezma la población paraguaya. A partir de este hecho histórico trascendental Paraguay se inserta en la economía mundial como país proveedor de materia prima preferentemente.

Es así que la producción agropecuaria ha sido históricamente el elemento principal en la estructuración económica y social del Paraguay. La forma como se ha organizado este sector agrícola y de sus características, han permeado las formas de vida de la sociedad paraguaya en su conjunto. Este carácter agro-dependiente de la economía paraguaya ha hecho que la disputa por la propiedad de la tierra y las relaciones de producción que de ella se derivan hayan estado en la base de los cambiantes procesos históricos que ha transitado el Paraguay (Rojas \& Ortega, 2007).

La posguerra fue un periodo de liberalización de la economía, que a partir de la venta masiva de las tierras públicas², principalmente a capitales anglo-argentinos y brasileños, y la reorientación de la producción hacia las exportaciones de materias primas, inició la integración del país de forma dependiente al capitalismo mundial (García, 1982 en Rojas \& Ortega 2007).

Así surgieron los enclaves 3 , latifundios que realizan la explotación de materias primas, fundamentalmente la yerba mate, el quebracho y la madera. Por otra parte, el excedente económico que generaban las exportaciones de estas materias primas, casi en su totalidad era transferido por los dueños del capital a sus países de origen, quedando un reducido porcentaje en el país. Paralelamente a estos enclaves, existía una gran cantidad de minifundios concentrados hacia la zona central del territorio, donde la densidad demográfica fue aumentando rápidamente, y donde se producía para abastecer las necesidades alimentarias de la población paraguaya (Rojas \& Ortega 2007).

Los enclaves productivos generaron relaciones de producción semi serviles, propias de la época colonial, que según Rojas \& Ortega (2007) no constituyeron una herencia del pasado, sino que estaban en directa relación con el proceso de acumulación del capital internacional, a través de la exportación de los productos mencionados y la transferencia del excedente económico.

Para estos autores la economía paraguaya está basada en el modelo rural dual de latifundio-minifundio, sin que en este país se haya desarrollado un proceso de industrialización por sustitución de importaciones como los generados en los países de la región. El modelo de desarrollo económico estuvo siempre puesto en cubrir las necesidades de los mercados

\footnotetext{
2 Entre 1884 y 1914 se vendieron más de 20 millones de has, aproximadamente la mitad del territorio nacional.

3 Régimen socio-económico implementado en un espacio geográfico para incorporar la lógica capitalista en las sociedades "atrasadas" de América Latina.
} 
internacionales.

La crisis mundial de 1929 encuentra al Paraguay en un proceso de escasa o precaria industrialización y por otro lado con conflictos internos generados por la presión por la tierra, por parte de los campesinos, obreros manifestándose por el reconocimiento de mayores derechos, más el auge triunfalista existente después de la Guerra del Chaco (1932-1935) generan una revuelta popular en febrero de 1937. Este movimiento encabezado por un militar combatiente en las contiendas de la Guerra del Chaco, va llegar al poder e impulsa un proyecto de reencause nacional propiciando una reforma agraria radical, destinada a afectar a los grandes latifundios y enclaves extranjeros fomentando el desarrollo de la industria en el país, creando nuevas instituciones en el área de la salud, agricultura y trabajo. Debido a las presiones internas de grupos de poder afectados por estas reformas este movimiento finalmente es derrocado un año después.

El carácter tardío del desarrollo en Paraguay, obligaba en el contexto del capitalismo internacional, a desarrollar fuerzas productivas desde el Estado, debido a que el sector privado no contaba con la capacidad para hacerlo debido a su carácter de productor primario auxiliar de los enclaves extranjeros. Es por eso que en la década del 40, se inicia el proceso de acumulación desde el Estado con un carácter patrimonialista y autoritario que llegará a su auge con el régimen dictatorial de Alfredo Stroessner (1954-1989).

Es así que en la década del 50, en los inicios del régimen dictatorial stronista, se da el agotamiento del modelo basado en el "enclave" y se comienza a desarrollar una nueva etapa en la estructura económica y social vigente. Este cambio se ve afianzado a partir de dos factores importantes: por una parte, los planes de estabilización del régimen dictatorial a nivel interno, caracterizado por la eliminación de toda oposición y por la otra, una fuerte alianza con los EEUU a través de la expansión de la asistencia técnica y financiera.

En este nuevo ciclo económico la presencia paraguaya en el mercado mundial se va dar a través de rubros como el algodón, la soja y el ganado. La consecuencia inmediata al fomento de estos rubros de exportación se vio en las comunidades campesinas e indígenas quienes asistieron a la invasión de sus territorios, cambiados su forma de relacionamiento y sobrevivencia, lo que desembocó en la migración campo ciudad y campo exterior del país.

El régimen dictatorial stronista se mantuvo 35 años en el poder llevando adelante un proceso de modernización conservadora, conjugando cambios sociales y económicos con cambios culturales y políticos. La Dictadura militar más larga en América Latina y en Paraguay, representó la negación absoluta de la vida, de la libertad, de la dignidad humana y de la justicia. El Estado -a través de sus organismos de seguridad- se constituyó en una herramienta eficiente de terror al servicio de los intereses geopolíticos de los EUA4 4 .

En el tiempo que va de $1975-1980$ se observa un auge económico ${ }^{5}$, la economía interna se dinamiza con la construcción de la Central Hidroeléctrica de Itaipu, que tuvo como consecuencia directa la ampliación del sector de la construcción civil y el fortalecimiento de las nuevas líneas de

\footnotetext{
$4 \mathrm{Al}$ comenzar la década del setenta todos los países de la región tenían gobiernos militares de derecha que compartían la ideología de la Doctrina de Seguridad Nacional formulada en los Estados Unidos al influjo de la "guerra fría", basaba en la concepción de que existía un supuesto estado de "guerra total", aunque no declarada, entre el "mundo democrático" y el comunismo. Para hacer frente a esta "guerra" todas las actividades políticas, económicas y sociales de un país quedaban subordinadas a la seguridad nacional, la cual era considerada un prerrequisito funcional para la supervivencia misma de la nación. Cada Ejército latinoamericano se plantea el problema de la seguridad nacional a partir de la hipótesis de la existencia de un "enemigo interno (Boccia, 2004).

5 En 1973 se firma el tratado de Itaipú y comienza el plan denominado "marcha hacia el este", construyéndose nuevas rutas, el puente internacional de la Amistad, la central hidroeléctrica y el puerto franco en Paraguay, Brasil (Coronel, 2011).
} 
producción, particularmente lo referente a la industria de metales y la artesanía en el período 1972-1982.

Este es el momento del incremento de la población urbana ${ }^{6}$ a partir de un aceleramiento migratorio tardío, que al decir de Brustein (2008) se dio más que por la atracción de oportunidades en la ciudad, por expulsión de la población rural debido a escasas oportunidades del empleo rural. Todos estos aspectos modificaron la relación urbano-rural generando por primera vez un incremento de la población urbana que amplía el mercado interno y el trabajo asalariado en el Paraguay. Un papel importante dentro de esta conformación de la masa urbana fue la ampliación de la esfera estatal, a través de la creación de instituciones de servicios estatales tales como agua, luz, teléfono, etc. (García, 2011).

En 1989 se da la caída de la dictadura militar, después de 35 años en el poder, se inicia el partido colorado continúa en el gobierno, pero con un nuevo plan económico en marcha y es así que en la primera mitad de la década del 9o Paraguay ingresa en el proceso neoliberal , aplicando la mayor parte del recetario de las reformas de primera generación, durante el gobierno del General Rodríguez. Las reformas de primera generación, fueron establecidas por el Consenso de Washington, concebidas como reformas económicas para lograr el crecimiento económico. Entre las reformas implementadas en el país se encuentran: a) Liberalización financiera y del tipo de cambio, b) Liberalización de la Inversión Extranjera Directa y c) Las privatizaciones. (Rojas, 2011).

Las privatizaciones encontraron fuerte resistencia por parte de varios sectores del propio Partido Colorado (de gobierno), por la importante clientela política que manejaban a través de las empresas públicas, además de estos tanto

6 Para 1982 la población urbana tenía 1295345 habitantes, construyéndose en el 42,8 \% del total poblacional (DGEEC, 2002). el movimiento sindical y el campesino tuvieron una activa resistencia con movilizaciones que alcanzaron su auge en el periodo presidencial de Luis González Machi (1999-2003) que dieron por terminado el periodo de privatizaciones de entes públicos (Rojas, 2011).

Posteriormenteconlasprivatizaciones públicas paradas y las influencias regionales de cambios políticos hacia la izquierda, Paraguay tendrá su alternancia política en el 2008, con la asunción al poder de Fernando Lugo, quien logra canalizar las demandas de las organizaciones sociales, algunos partidos de izquierda y aliado con uno de los partidos tradicionales el partido liberal logra establecer un gobierno con aires democratizadores. La larga deuda social, un Estado marcado por la clientela política, son las características que marcan este inicio de gobierno no obstante, el mismo genera una impronta distinta, se desarrollan políticas tendientes a responder las demandas sociales históricas (Palau, 2009).

Este gobierno posteriormente es derrocado por un golpe parlamentario en el 2012 y a partir de allí el proyecto de corte neoliberal es nuevamente retomado por los gobiernos posteriores.

\subsection{Origen e institucionalización del Trabajo Social en Paraguay}

Para García (1996) existen dos componentes vinculados entresíy presentes en el surgimiento del Trabajo social en Paraguay; por un lado al estancado proceso económico paraguayo, caracterizado por la no industrialización y por lo tanto tuvo un tardío proceso de urbanización. El otro componente es la aparición, en el escenario nacional, de la "cuestión social" entendida como la activa participación de los trabajadores en las primeras décadas del siglo XX en el escenario nacional.

La misma plantea que en términos de propuesta teórica ideológica el trabajo social paraguayo recibió la influencia del Movimiento Médico Higienista y de la intervención 
religiosa, con la fundamentación de mejorar las respuestas a los problemas sociales. Es con estas características que en el año 1939, se crea la Escuela Polivalente de Visitadoras de Higiene, bajo la iniciativa del Ministerio de Salud Pública y Bienestar Social.

Con relación al movimiento médico higienista, la autora señala que este movimiento surge en el comienzo del siglo XX, en los países industrializados en el contexto de las demandas de mayor cantidad de mano de obra para la producción. Esta propuesta plantea la relación entre las condiciones de higiene, condiciones de salubridad para prevenir algunas enfermedades. El área de preocupación clave de los higienistas eran las cuestiones de la dimensión moral, que entrelazan los problemas sociales más visibles y los de la salud pública. Esta corriente de pensamiento está presente así en el espacio de formación a través de las materias tales como, Higiene individual pública y escolar, Educación de la castidad, Norma Sociales de urbanidad, entre otras (García, 1996, p. 43).

En el caso paraguayo indica García (1996), esta propuesta se ajusta al contexto del país conjugando tareas asistenciales con contenidos y orientaciones conciliadoras dirigidos a calmar los descontentos sociales manifestados en los primeros años del siglo XX.

En lo referente a la intervención religiosa y la asistencia, la misma plantea que en los inicios de la cuarta década del siglo XX, el corporativismo militar con el gobierno autoritario que se inaugura colocó determinaciones ideo política y cultural en los diversos espacios de la vida social paraguaya condicionando la intervención religiosa y a su vez la asistencia. Por lo que el contenido religioso ofreció al Trabajo social una dimensión material y simbólica que dio elementos para la intervención, encuadrada en la asistencia caritativa. Este contenido religioso propició la incorporación de los valores morales y espirituales y ayudó a sustentar y efectivizar las tareas higienistas
(García, 1996, p. 49).

El médico higenismoy la intervención religiosa son para García (1996) los dos grandes patrones ideo-culturales en los modelos de asistencia de las primeras décadas en el Paraguay y que presentaban en común las siguientes orientaciones centrales:

- el respeto a las instituciones, el gobierno, a la patria y a los superiores en general.

- la preservación de las buenas costumbres, la moral cristiana y la ética, entendida como orden y obediencia a lo establecido por las autoridades.

- El celoso cuidado a la paz pública, con reglamentos establecidos y con precondiciones a nivel de juicio valorativo, imponiendo lo apropiado, correcto, justo.

Estos dos patrones ideo culturales son funcionales con la orientación militar presente a nivel nacional y con su clara orientación disciplinaria de orden y paz (García, 1996, p. 106).

\subsection{La transición democrática, replanteos en la formación profesional e intentos de la ruptura con el pensamiento conservador}

Vale recordar también que las búsquedas de redefiniciones en el trabajo social en la etapa de la transición a la democracia paraguaya (1989 en adelante), estuvieron centradas en las tensiones generadas en la materia práctica profesional, fundamentalmente orientada hacia el cómo hacer de la práctica entendiendo la metodología como algo estrictamente operativo.

Los cambios que se dieron en el $89^{7}$

7 La lucha universitaria en los primeros meses del
año 1989, tras el derrocamiento de la dictadura, toma
como su principal reivindicación la protesta contra
las autoridades universitarias. Así se emprende una
lucha conjunta entre los centros de estudiantes de las
Escuelas de Enfermería, Obstetricia y Servicio social
buscando una reorientación de la carrera y cambios 
en la carrera de Trabajo Social, (con un nuevo currículo en 1990) constituyeron un salto significativo para la historia del Trabajo Social paraguayo, representando el primer intento de ruptura con el modelo de Trabajo Social de carácter conservador. Con ese Trabajo Social moralista, con tradición de la intervención religiosa, ideológicamente coherente con los valores tradicionales de la época, así como con la influencia norteamericana con una fuerte tendencia hacia la aplicación de técnicas.

Continuarán a partir de este momento y de manera sucesiva las movilizaciones y consecuentes cambios, en torno a la búsqueda de la superación del legado conservador solo que centrándose preferentemente en la materia práctica. Así, en 1994 se dan los primeros cambios (post 89) a partir del movimiento estudiantil que se moviliza y reclama cambios ante las diversas dificultades ${ }^{8}$ sentidas de los estudiantes en la práctica. En 1996, se plantea una nueva propuesta de práctica, la llamada práctica integrada. Al año siguiente $y$ ante las numerosas contradicciones presentadas en la implementación de Práctica Integrada, se vuelve a modificar la materia y sin abandonar los Centros de Prácticas establecidos en el 96, se presenta una nueva propuesta, la práctica por niveles que suponía "un mayor compromiso con los sectores populares", reclamo permanente del sector estudiantil; el 97 fue considerado un año de transición.

Un nuevo diseño de la práctica se presenta en el 98, que parte de cuestionamientos hacia los anteriores

profundos en la institución. Como resultado de la lucha estudiantil en la carrera de Servicio Social se dan varios cambios: pasa denominarse "Trabajo Social", asume una nueva directora, nominada por el sector estudiantil, cambia el plantel docente, ingresando profesionales no comprometidos con la dictadura y con destacada trayectoria académica, así “corrientes innovadoras y progresistas en relación a la realidad paraguaya contribuyeron a polemizar el rol del Trabajo Social paraguayo".

8 Documento de la jornada de recuperación de la memoria, 1997. programas de práctica. Se propone dejar de lado "a tarea asistencialista o funcionalista" para pasar a ser el "promotor de las transformaciones sociales", la salida de las instituciones, el Método dialéctico y la sistematización (como "el enlace académico entre la realidad y la teoría") como los ejes que guiarán la propuesta. Pero contradictoriamente no proponía ningún lineamiento metodológico. En 1999, se realiza una nueva revisión y su respectivo cambio.

En toda esta etapa señalada (década de los noventa) se presenta en términos discursivos reiteraciones importantes referidas a la intención de que esta práctica esté volcada al servicio del sector popular, lo cual, si bien es un avance (considerando que durante la dictadura militar stronista 19541989, los discursos y programas de estudios de la práctica se mostraban funcionales al sistema imperante); resultaba limitada debido que se constataron limitaciones a la hora de estructurar una "práctica" académica que articule con "o popular"9.

Además, la discusión y las propuestas, en el periodo que se viene mencionando estuvieron marcadas fuertemente por el cómo hacerya partir del cual surgen diversas formulaciones metodológicas referidas a lo estrictamente operativo ${ }^{10}$. Pero además se dio también un periodo de rechazo a todo tipo de delineamiento metodológico

\footnotetext{
9 Cabe señalar que en la decena del 90 la formación profesional del trabajo social en Paraguaya, sufrió varios replanteamientos generadas de demandas estudiantiles y docentes que implicaron modificación del currículo en 1990, paro estudiantil en el 94, destitución de la directora, en el 1996 se da una modificación de la propuesta de práctica profesional estructurada por etapas del proceso metodológico del Celats (1982), esta propuesta entra en crisis nuevamente y es modificada por otra propuesta en los años 1997 y 1998. Esta propuesta hace una crítica fuerte al trabajo social en las instituciones estatales y plantea que los centros de prácticas tendrían que ser en espacios abiertos y que es desde la práctica que se estructura la intervención.

10 Analizando los programas e instrumentos de evaluación las prácticas de todos estos años se puede notar una excesiva preocupación por competencias técnicas.
} 
planteándose la práctica concreta como el punto de partida para el conocimiento de la realidad.

Se puede afirmar que el incipiente debate generado por la incorporación de algunostextos enlaliteraturadetrabajosocial sobre la mediación teórica, las diferentes crisis desatadas con la implementación de varias propuestas de práctica, especialmente la del 98 sin estrategias metodológicas implicó que el cuerpo docente tome conciencia de necesidad de conocer los nuevos marcos teóricos de la disciplina y de entender más sobre cómo abordar la realidad. A partir de esta sensibilización, se plantea un proceso de capacitación docente del que formó parte todo el estamento. Además es el momento en que se comienza a perfilar sobre la necesidad de un cambio curricular para la carrera. Todo este tiempo es caracterizado como el de mayor búsqueda de formación teórica sobre las matrices del Trabajo Social.

Para García (2007) el periodo en que se inicia el Movimiento de Reconceptualización en Paraguay, es el 89 y se prolonga a lo largo de la década de los noventa, porque según la autora es el momento en que los cuestionamientos a las imposiciones económicas, políticas, sociales y culturales, se empezaron a expresar y no se observa alguna experiencia colectiva del Servicio Social paraguayo, en protesta o enfrentamiento a las disposiciones dictatoriales, antes de 1989.

Continuando con el proceso de cambios curriculares, en el año 2001, el Diseño Curricular de la Escuela de Trabajo Social, por Resolución Nro. 8542oo-o1, entró en vigencia. Este nuevo diseño curricular implicó, entre otras cosas, la adecuación de la estructura administrativa y académica de la Escuela, fundamentalmente porque se planteó como régimen semestral, incorporando coordinaciones que se estructuraron en base a propuesta académica (Teoría Social y conocimientos conexos para la intervención, Procesos Sociales y Realidad
Nacional, Trabajo Social, Historia y Método), según consta en el documento de presentación curricular.

Posterior a la reforma curricular del 2001 este proceso de reflexión análisis y capacitaciones es cortado a partir de la adhesión de la carrera de Trabajo Social a la Facultad de Filosofía ${ }^{11}$ en el 2004, en este espacio institucional la carrera entra en un proceso de contramarchas, debido a que la política institucional de la facultad implicó la supresión de todo el proceso de reflexión y análisis generados en años anteriores y curricularmente se decide pasar de un régimen semestral a un régimen anual en todos los cursos, con las consecuencias administrativas, jurídicas y académicas que esto conlleva. A partir de todas estas arbitrariedades los docentes y estudiantes de la carrera inician un proceso de lucha por la desanexión de la Facultad de Filosofía, generando la creación del Instituto de Trabajo Social dependiente esta vez del Rectorado de la Universidad Nacional de Asunción.

El proceso de construcción de una institucionalidad que gestiona con cierta autonomía y práctica democrática la carrera de Trabajo Social, posibilitó volver a retomar después de trece años las reflexiones sobre las mediaciones teóricas necesarias para pensar la profesión.

\section{A modo de síntesis; una aproximación a la perspectiva crítica en Trabajo Social en la formación profesional en Paraguay}

Recuperando la idea de que el trabajo sociales tributaria del pensamiento conservador y como tal un proyecto generado para acallar las manifestaciones de la cuestión social generadas a finales del siglo XIX. Por otro lado siguiendo a García (1996) el Trabajo Social paraguayo tiene características conservadoras, puesto

11 Anteriormente la Carrera de Trabajo Social estaba inserta en el Instituto Andrés Barbero dependiente de la Facultad de Medicina. 
que su propuesta teórica e ideológica estuvo marcada por el Médico Higenismo y la influencia de la iglesia católica. Estas influencias en realidad sintonizan con los orígenes del Trabajo Social en la región ${ }^{12}$. Por otro lado se ha visto que con el movimiento de la reconceptualización se da ruptura con este legado conservador y la profesión inicia un proceso de elaboración hasta la actualidad de propuestas superadoras al escepticismo, parcialidad en el análisis.

Es sabido que hoy los profesionales de Trabajo Social apuestan al desarrollo de procesos de intervención deliberativos, participativos e interactivos, fundamentados en perspectivas comprensivas y socio críticas para orientar el desempeño profesional, autores tales como Aquín (2003, 2006), Matus (1999), Rozas (1998, 2001) y Carballeda (2004, 2006, 2008). Plantean la necesidad de identificar la necesidad de superar la mirada instrumental de la intervención, tratando de ubicar críticamente, la acción desde Trabajo Social en un mundo globalizado, en el que la incertidumbre transversaliza la actividad humana.

Fundamentar la intervención desde Trabajo Social implica superar la dicotomía de la profesión (hacer) y disciplina (conocer-saber), entender ambas forman parte de un mismo proceso, es a partir de esto que se plantea como fundamental generar espacios de formación donde se puedan acentuar las competencias sobre la reflexión epistemológica, recogiendo todos los aportes generados en la profesión en estos últimos años.

Por otro lado se ha mencionado que la perspectiva histórica crítica plantea que es indispensable entenderal capitalismoy para ello es preciso considerarlo en su condición de categoría histórica, social y económica, como un modo de producción asociado no sólo a la explotación del/a trabajador/a, sino también a un sistema de ideas y a una fase histórica del mismo, ubicando Paraguay en

12 Ver Alayon, N. (1980). Historia del trabajo social en Argentina. Buenos Aires: Celats. un papel subordinado del desarrollo del capitalismo central. Por otro lado, al ser un país ubicado en medio de dos grandes países sudamericanos, su desarrollo estuvo marcado por su papel subalterno o auxiliar a las grandes economías de la región.

En cuanto al desarrollo de las fuerzas productivas a nivel interno, generada por este particular desarrollo capitalista periférico, se ha mencionado que estuvo caracterizado por el tinte represivo y conservador, tanto por el origen del trabajo social, así como por la larga dictadura que soportó el país por más de 35 años. Este proceso configuró una determinada forma de vida en sociedad, marcada por el miedo, la inhibición y la individualización de los problemas sociales.

Hoy a más de 26 años de vida democrática, se presencia la aparición de nuevos movimientos sociales que ocupan la escena pública, con reivindicaciones del más variado tipo, por otro lado también se presencia el resurgir de un discurso que recuerda y reivindica el pasado dictatorial y las formas de vida que este modo dejó. Ante este escenario de nuevos y viejos discursos reaparecidos, se hace imprescindible una lectura de sentidos desde las distintas profesionales y en especial desde el Trabajo Social. Ahora bien ¿Cómo se dará cuenta de estos desafíos, si nuestro acumulado teórico-práctico está anclado con formas de pensar la práctica desprovista de mediaciones teóricas que la expliquen? ¿Cómo se podría pensar en las formas devida generadas de este sistema de producción, sin las herramientas que nos posibiliten comprenderla? Estos interrogantes plantean la necesidad de profundizar la reflexión, investigación sobre los nexos entre las categorías teóricas explicativas de la realidad y las particularidades que estas asumen o asumirán en el proceso paraguayo.

Otro punto importante dentro de esta matriz es reconocer la inexistencia de tradiciones en el pensamiento social paraguayo que posibiliten la comprensión 
de la formación social paraguaya desde una visión de totalidad. Esta limitación hace que el proceso social paraguayo sea entendido como proceso lineal, es decir, en contextos alejados de los problemas concretos con los que el trabajador social interviene.

El poco desarrollo de las ciencias sociales es también otro factor en ese sentido, que ayudó a no poder dar un salto cualitativo como trabajadores sociales. La no existencia de tradiciones desde las ciencias sociales paraguayas que ayuden a hacer puentes comunicaciones entre lo concreto visto en la realidad y las categorías generales del pensamiento, asociada al legado conservador existente en la profesión, hacen que el análisis de muchas temáticas sociales sean naturalizadas, antes que problematizadas como manifestaciones de relaciones estructurales de larga data.

En fin, por todos los elementos planteados en este trabajo se puede decir que la perspectiva crítica del Trabajo Social en Paraguay se encuentra aún en un momento incipiente, son muchos los nexos que quedan por establecer. No es difícil pero solo dependerá del compromiso y la claridad teórico-política de los cuadros profesionales implicados con la formación para ir desarrollando diversas estrategias y fortalecer el proyecto profesional crítico en Paraguay.

\section{Referencias Bibliográficas}

Alayon, N. (1980). Historia del trabajo social en Argentina. Buenos Aires: Celats.

Aquín, N. (2003). Ensayo sobre Ciudadanía. Reflexiones desde el Trabajo Social. Buenos Aires: Espacio.

Aquín, N. (2006). Reconstruyendo lo social. Prácticas y Experiencias de Investigación desde el Trabajo Social. Buenos Aires: Espacio.

Boccia, A. (2004). Diccionario Usual del Stronismo. Asunción: Servilibro.

Brunstein, J. (2008). Tendencias de las políticas públicas y la pobreza rural campesina en Paraguay. In A.
Cimadamore (Ed.), La economía política de la pobreza (pp. 339-368). Buenos Aires: CLACSO.

Carballeda, A. (2004). Del desorden de los cuerpos al orden de la sociedad. Buenos Aires: Espacio Editorial.

Carballeda, A. (2006). El Trabajo Social desde una mirada histórica centrada en la intervención: del orden de los cuerpos al estallido de la sociedad. Buenos Aires: Espacio Editorial.

Carballeda, A. (2008). Los cuerpos fragmentados. Buenos Aires: Editorial Paidós.

Coronel, B. (2011). Breve interpretación marxista de la historia paraguaya (15372011). Asunción: Arandura.

Dirección General de Estadisticas Encuestas y Censos. (2002). Diagnóstico de población. Recuperado de http:// www.dgeec.gov.py/Publicaciones/ Biblioteca/Web\%2oParaguay\%20 Total\%2oPais/3\%2oDiagnostico\%2o poblacion.pdf

García, S. (1996). Bases para un análisis del origen del trabajo social en Paraguay. Asunción: Base Is.

García, S. (1997). Gênese e os processos de institucionalização do Serviço Social no Paraguai (Dissertação de Mestrado). Universidad Federal de Rio de Janeiro, Rio de Janeiro.

García, S. (2007). La reconceptualizacion del Trabajo Social en Paraguay. In N. Alayon (Ed.), Trabajo Social latinoamericano: a 40 años de la reconceptualización (pp. 271-289). Buenos Aires: Espacio Editorial.

Iamamoto, M. (1997). O Serviço Social na contemporaneidade: trabalho $e$ formação profissional. $4^{\text {a }}$ ed. São Paulo, Cortez.

Manrique Castro, M. (1982). De apóstoles a agentes de cambio. Lima: CELALTS.

Matus, T. (1999). Propuestas contemporáneas en Trabajo Social. Hacia una intervención polifónica. Buenos Aires: Espacio Editorial. 
Montaño, C. (1999). El Servicio Social frente al neoliberalismo. Cambios en su base de sustentación funcional laboral. Boletín Electrónico Surá, (41).

Montaño, C. (200o). La naturaleza del servicio social: un ensayo sobre su génesis, su especificidad y su reproducción. $2^{\mathrm{a}}$ ed. San Pablo: Cortez.

Muñoz, N. E. \& Vargas, P. (2013). A propósito de las tendencias epistemológicas de Trabajo Social en el contexto Latinoamericano. Katalisis, 16(1), 122130.

Netto, J. P. (1998). Capitalismo monopolista y Servicio Social. San Pablo: Cortez.

Netto, J. P. (2002). Cinco notas a propósito de la cuestión social. In E. Borgianni \& M. Y. Guerra (Ed.), Servicio Social Crítico (pp. 55-69). San Pablo: Cortez.

Palau, M. (2009). Gobierno de Lugo: ¿escenario de construcción de alternativas? In L. Rojas (Ed.), Gobierno de Lugo. Herencia, gestión y desafíos (p. 119-130). Asunción: s.n.

Parra, G. (s.f). Aportes al Análisis del Movimiento de Reconceptualización en América Latina. Recuperado de https://www.google.com. py/webhp? sourceid =chromeinstant\&ion $=1 \&$ espv $=2 \&$ ie $=U T F-$ $8 \# \mathrm{q}=\mathrm{gustavo} \% 2$ o parra $\% 2$ o reconceptualizacion
Rojas, L. \& Ortega, G. (2007). Corporaciones transnacionales y el modelo de producción agrícola en Paraguay. Asunción: Base-Is.

Rojas, L. (2011). Las reformas neoliberales de Primera y Segunda Generación en el Paraguay. In L. Rojas. (Ed.), $L a$ economía paraguaya bajo el orden neoliberal (pp. 13-48). Asunción: Base IS, SEPPY, RIS.

Rojas, L. (2012). La economía paraguaya independiente. In L. Rojas (Ed.), Proceso histórico de la economía paraguaya (pp. 149-178). Asunción: Secretaría Nacional de la Cultura.

Rozas M. (1998). Una perspectiva teórico metodológico de la intervención en Trabajo Social. Buenos Aires, Espacio Editorial.

Rozas, M. (2001). Laintervención profesional en relación con la cuestión social. El caso del trabajo social. Buenos Aires. Espacio Editorial. 